\title{
Hemócitos de Bradybaena similaris e Megalobulimus abbreviatus (Gastropoda, Stylommatophora)
}

\author{
Roberta A. Rohr ${ }^{1,2} \&$ Suzana B. Amato²
}

\begin{abstract}
1. Programa de Pós-Graduação em Biologia Animal, Departamento de Zoologia, UFRGS.
2. Departamento de Zoologia, Instituto de Biociências, Universidade Federal do Rio Grande do Sul. Av. Bento Gonçalves, 9500, Prédio 43435, Sala 202b, 91501-970, Porto Alegre, RS, Brasil. (sbamato@ufrgs.br; endereço eletrônico para correspondência: robertarohr1@gmail.com)
\end{abstract}

\begin{abstract}
Hemocytes of Bradybaena similaris and Megalobulimus abbreviatus (Gastropoda, Stylommatophora). Hemocytes act in the defense system against invading organisms, foreign particles aiding the recognition of what is own to the body of gastropods and what is not. Information and studies on the hemocytes in species of mollusks healthy (no infections), especially in Bradybaena similaris (Fèrussac, 1821) and Megalobulimus abbreviatus (Bequaert, 1948) are scarce. Therefore, this work aims at characterization and quantification of hemocytes present in the hemolymph of these two species. In this work three cell types were identified in the hemolymph of both species: round cells, hyalinocytes and granulocytes. The three types of hemocytes were measured, and the average of total diameter and the nucleus for each was calculated. On B. similaris, the average diameter of round cells was $10.7 \mu \mathrm{m}$, of hyalinocytes was $20 \mu \mathrm{m}$ and of granulocytes was $25.4 \mu \mathrm{m}$. On M. abbreviatus, the average diameter of round cells was $11.7 \mu \mathrm{m}$, of hyalinocytes was $21.5 \mu \mathrm{m}$ and of granulocytes was $30.5 \mu \mathrm{m}$. Although the hyalinocytes have similar averages between B. similaris and M. abbreviatus, the cells were demonstrated significant differences in their total diameter and size of the nucleus $(p<0.0001)$. The average density of cells per $\mathrm{ml}$ without distinction of cellular type was 197,813 cells $/ \mathrm{ml}$ for M. abbreviatus, and 416,333 cells/ml for B. similaris. The most frequent hemocytes in M. abbreviatus and B. similaris were hyalinocytes, unlike other gastropods.
\end{abstract}

KEYWORDS. Granulocytes, hyalinocytes, Mollusca, round cells.

RESUMO. Os hemócitos atuam no sistema de defesa contra organismos invasores e partículas estranhas, auxiliando o reconhecimento do que é próprio do corpo dos grastrópodes e o que não é. São escassas as informações e estudos sobre os hemócitos em espécies de moluscos saudáveis (sem infecções), principalmente em Bradybaena similaris (Fèrussac, 1821) and Megalobulimus abbreviatus (Bequaert, 1948). Portanto, este trabalho tem como objetivos a caracterização e quantificação dos hemócitos presentes na hemolinfa destas duas espécies. Neste trabalho, foram identificados três tipos celulares na hemolinfa de ambas espécies: as células redondas, hialinócitos e granulócitos. Os três tipos de hemócitos foram medidos e foi calculada a média do diâmetro total e do núcleo para cada um deles. Para B. similaris, o diâmetro médio das células redondas foi de $10,7 \mu$ m, dos hialinócitos foi de $20 \mu \mathrm{m}$ e dos granulócitos de 25,4 $\mu \mathrm{m}$. Para M. abbreviatus, o diâmetro médio foi de 11,7 $\mu \mathrm{m}$ para as células redondas, de 21,5 $\mu \mathrm{m}$ para os hialinócitos e de 30,5 $\mu \mathrm{m}$ para os granulócitos. Embora os hialinócitos possuam médias parecidas entre B. similaris e M. abbreviatus, foram detectadas diferenças significativas do diâmetro celular total e diâmetro do núcleo $(p<0,0001)$ dessas células entre as espécies estudadas. A densidade média de células por $\mathrm{ml}$, sem distinção de tipo celular foi de 197.813 células $/ \mathrm{ml}$ para $M$. abbreviatus, e de 416.333 células $/ \mathrm{ml}$ para $B$. similaris. Diferentemente de outros gastrópodes, os hemócitos mais frequentes em M. abbreviatus e em B. similaris foram os hialinócitos.

PALAVRAS-CHAVE. Células redondas, Granulócitos, Hialinócitos, Mollusca.

Os gastrópodes possuem um sistema de defesa diferenciado, se comparado com os vertebrados em geral, mas comum em todos os moluscos, não possuindo linfócitos, sistema de complemento, respostas a antígenos específicos e imunoglobulinas (BAYNE, 1983; KLeIN, 1989). Apesar disso, o sistema de defesa é capaz de perceber pequenas diferenças do que pertence ou não ao seu corpo. $\mathrm{O}$ sistema de defesa interno dos gastrópodes é composto por um mecanismo humoral, que inclui proteínas efetoras, tais como peptídeos antimicrobianos, fenoloxidase e lisozima. As proteínas efetoras atuam na primeira linha de defesa do organismo, sendo sintetizadas basicamente nos hemócitos e armazenadas em seus grânulos (BACHÈre et al., 2004). Um mecanismo celular também faz parte desse sistema de defesa interno, o qual é constituído por hemócitos. Os fatores solúveis encontrados na hemolinfa dos moluscos incluem aglutinas, opsoninas, enzimas, inibidores enzimáticos, substâncias reativas de grupos sanguíneos e substâncias imobilizadoras de miracídios. A imunidade humoral é mediada por lectinas, que são proteínas sintetizadas por hemócitos, com afinidade específica a carboidratos (ZeLCK et al., 1995). Os fatores solúveis da hemolinfa e os hemócitos agem juntos na destruição de material estranho ao corpo (Boulanger et al., 2006). Os hemócitos, que podem estar livres (circulantes na hemolinfa) ou fixos nos tecidos, se destacam na defesa. Mobilizam-se em direção às regiões onde aparecem as formas parasitárias, acumulando-se ao seu redor, atacando, formando cápsulas e/ou complexos encapsulantes para a inativação e absorção dos parasitos (Lie et al., 1975; JEONG et al., 1983). Possuem também como funções: reparação tecidual, limpar a hemolinfa e o tecido conjuntivo fagocitando partículas estranhas ou encapsulando material estranho, e sintetizam fatores para a defesa humoral (VAN DER KNAAP \& LOKER, 1990).

A maioria dos estudos com hemócitos de gastrópodes referem-se a espécies dos gêneros Biomphalaria (Preston, 1910) e Lymnaea Lamarck, 1799 sob condições, ou não, de infecção (MülLER, 1956; SMINIA, 1972; Harris, 1975; Yoshino, 1976; Cheng \& Guida, 1980; LoVerde et al., 1982; JeONG et al., 1983; JoKy et al., 1983; SMinia et al., 1983; BarRaco et al., 1993; BezerRa et al., 1997, 2003; Matricon-Gondran \& Letocart, 1999; Russo \& Lagadic, 
2004; Barbosa et al., 2006; SAntos \& Diniz, 2009; SAntos et al., 2011; CAVAlCANTI et al., 2012). O conhecimento sobre o sistema imunológico dos gastrópodes é importante, principalmente o conhecimento dos hemócitos de caracóis não infectados, para que em futuros estudos, seja possível avaliar a ação do parasitismo sobre o sistema de defesa do hospedeiro. O objetivo deste trabalho é caracterizar e quantificar os hemócitos de duas espécies de gastrópodes, sendo uma exótica, Bradybaena similaris (Fèrussac, 1821), e outra nativa, Megalobulimus abbreviatus (BEQUAERT, 1948).

\section{MATERIAL E MÉTODOS}

Coleta e manutenção dos gastrópodes. Vinte espécimes de $B$. similaris foram coletados no município de Canoas, RS, em ambiente antropizado (jardim). As coletas ocorreram em outubro de 2011 e em junho e julho de 2012. Dois espécimes de M. abbreviatus foram coletados em um ambiente também antropizado (terreno baldio), em Barra do Ribeiro/RS.

Os espécimes de ambas as espécies reproduziramse em laboratório, e espécimes nascidos de suas posturas foram utilizados na pesquisa. Os indivíduos foram mantidos em condições ambientais não controladas, no Laboratório de Helmintologia do Departamento de Zoologia da Universidade Federal do Rio Grande do Sul (UFRGS). Os gastrópodes foram acondicionados em caixas plásticas com substrato de serrapilheira e um recipiente plástico com água, para manter a umidade e suprir suas necessidades hídricas. A alimentação consistiu, basicamente, de folhas de couve.

Coleta e preparação dos hemócitos. As amostras de hemolinfa foram coletadas, diretamente, da cavidade pericárdica de 35 indivíduos de M. abbreviatus e 27 de $B$. similaris nascidos e criados em laboratório, ou seja, livres de infecção. Para a coleta utilizaram-se seringas estéreis Plastipak B-D, $1 \mathrm{ml}$ de capacidade, com agulhas microfinas II. Foi feito um pequeno orifício nas conchas, previamente limpas com etanol $70^{\circ} \mathrm{GL}$, sobre a região pericárdica para permitir a introdução da agulha. Foi coletado $0,1 \mathrm{ml}$ de hemolinfa por molusco, diluída na própria seringa, com solução salina fisiológica $0,65 \%$ até completar o volume de 0,5 ml. A hemolinfa foi então colocada sobre uma lâmina histológica em uma câmara úmida (placa de petri $12 \mathrm{~mm}$ de diâmetro com uma pequena porção de algodão embebida em água), onde permaneceu por 20 a 30 minutos para a formação de uma monocamada de células, de acordo com a técnica utilizada por Ford et al. (1993). Após a drenagem do sobrenadante, a lâmina foi removida da câmara úmida e os hemócitos foram fixados com metanol absoluto por, aproximadamente, 10 minutos. A coloração foi feita com Giemsa (diluído em água tamponada, na proporção de 1:9) por 30 a 35 minutos (CARNeiro \& DAEMON, 1997, 2002; HUMASON, 1972).

Quantificação dos hemócitos com Câmara de Neubauer. A quantificação dos hemócitos foi feita em
Câmara de Neubauer (NoDA \& LoKER, 1989). A contagem diferenciada dos hemócitos foi realizada em 20 campos ópticos escolhidos ao acaso, em microscópio. As lâminas com a hemolinfa foram observadas logo após a coleta do material e depois de 20 minutos de repouso, para verificar as diferenças existentes entre as células encontradas. A densidade dos hemócitos foi calculada aplicando a fórmula proposta por Ford et al. (1993), para cada um dos tipos celulares encontrados, separados por espécies. Também foi calculado o desvio padrão de cada tipo celular, em ambas as espécies.

Análise dos dados. Foi aplicado o teste D'Agostinho para verificar se o diâmetro celular total e do núcleo dos hemócitos encontrados em ambas as espécies possuíam distribuição normal. Através desta informação, foi possível utilizar o teste paramétrico $t$ de Student, para avaliar se existiam diferenças significativas entre o tamanho total e do núcleo entre os tipos celulares presentes na hemolinfa. Para a análise dos dados não paramétricos, diâmetro total e do núcleo dos hemócitos, foi aplicado o teste de MannWhitney (Wilcoxon rank-sum test). Para a realização de todas as análises estatísticas foi utilizado o programa BioEstat 4.0 (Ayres et al., 2005).

\section{RESULTADOS}

Morfologia dos hemócitos. Cem por cento das células da hemolinfa apresentavam forma arredondada logo que foram colocadas na câmara de Neubauer. Após 20 minutos, 60 a $80 \%$ dos hemócitos, inicialmente arredondados, espalharam-se sobre a lâmina e apresentaram projeções citoplasmáticas. A adesão das células sobre a lâmina possibilitou a diferenciação de três tipos celulares presentes na hemolinfa dos gastrópodes, classificadas como células redondas, hialinócitos e os granulócitos.

As células redondas (Figs 1, 2, 7) caracterizam-se por não possuírem projeções citoplasmáticas, especialmente em $M$. abbreviatus, enquanto que em $B$. similaris foram observadas algumas pequenas projeções. De maneira geral, estas células possuem forma esférica ou oval, com grande núcleo central ocupando quase todo o volume celular. O citoplasma está em apenas uma área estreita em torno do núcleo. O diâmetro médio das células foi semelhante entre as duas espécies, não tendo sido detectadas diferenças significativas $(p=0,96)$. O diâmetro máximo e mínimo das células aparesentaram variações dentre as espécies do presente estudo (Tab. I), mas estas variações não foram significativas $(p=0,16)$. Da mesma forma, não foram observadas diferenças significativas $(p=0,18)$ quanto ao diâmetro do núcleo. Em M. abbreviatus cerca de 5\% das células redondas apresentaram mais de um núcleo (Fig. 2).

Os hialinócitos (Figs 3, 8, 9) apresentam perfil polimórfico, núcleo localizado no centro da célula, ou algo excêntrico, citoplasma homogêneo, às vezes com alguns poucos grânulos. Essas células possuem projeções citoplasmáticas e foi possível observar pequenos agrupamentos celulares em M. abbreviatus. Também 

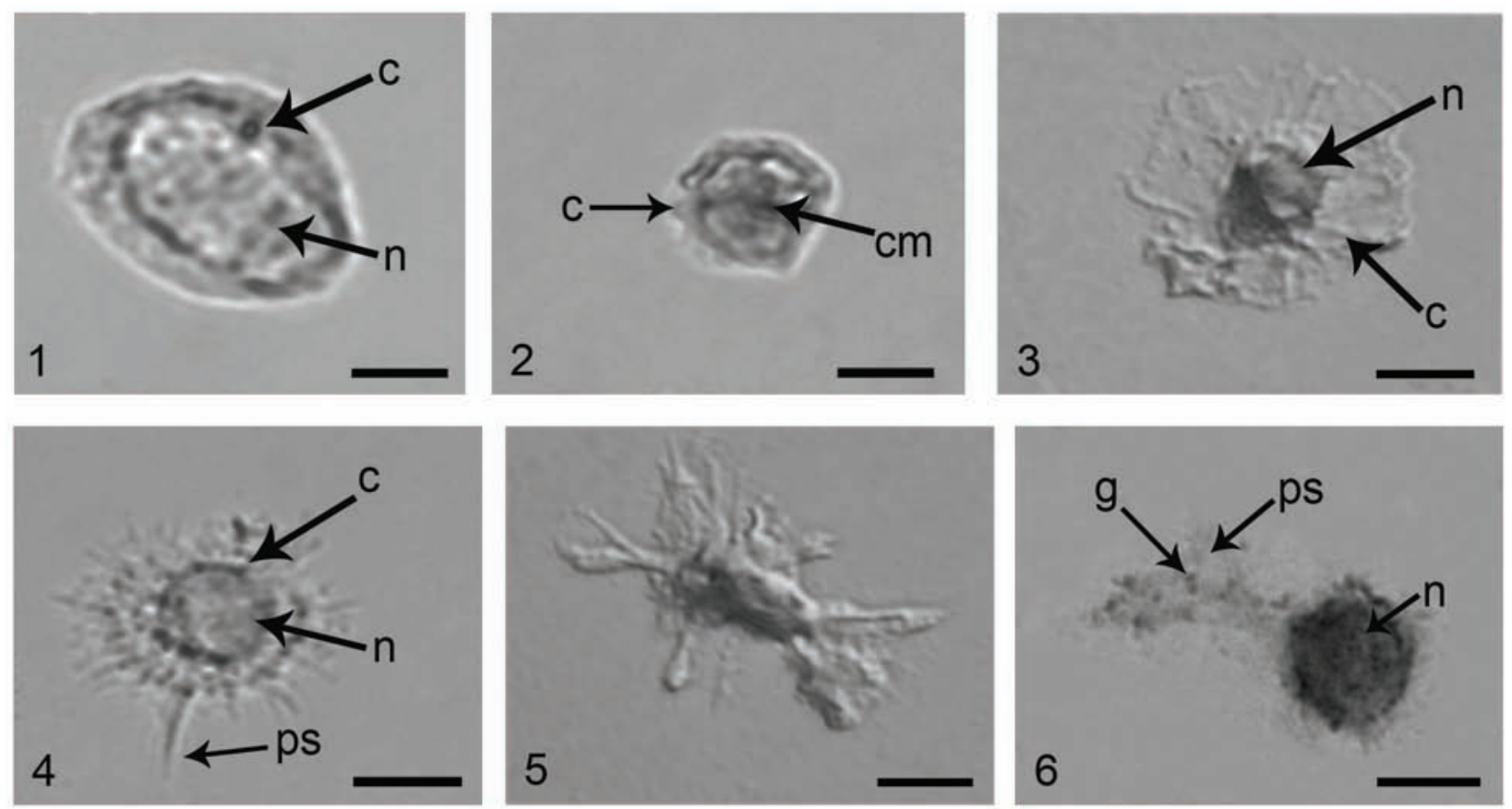

Figs 1-6. Tipos de hemócitos encontrados em indivíduos de Megalobulimus abbreviatus (Bequaert, 1948): 1, célula redonda; 2, célula redonda em divisão; 3, hialinócito; 4, granulócito; 5, granulócito com formato fusiforme; 6, granulócito com grânulos evidenciados (c, citoplasma; cm, célula em mitose; g, grânulo; n, núcleo; ps, pseudópodes). Barra=25 $\mu$ m.
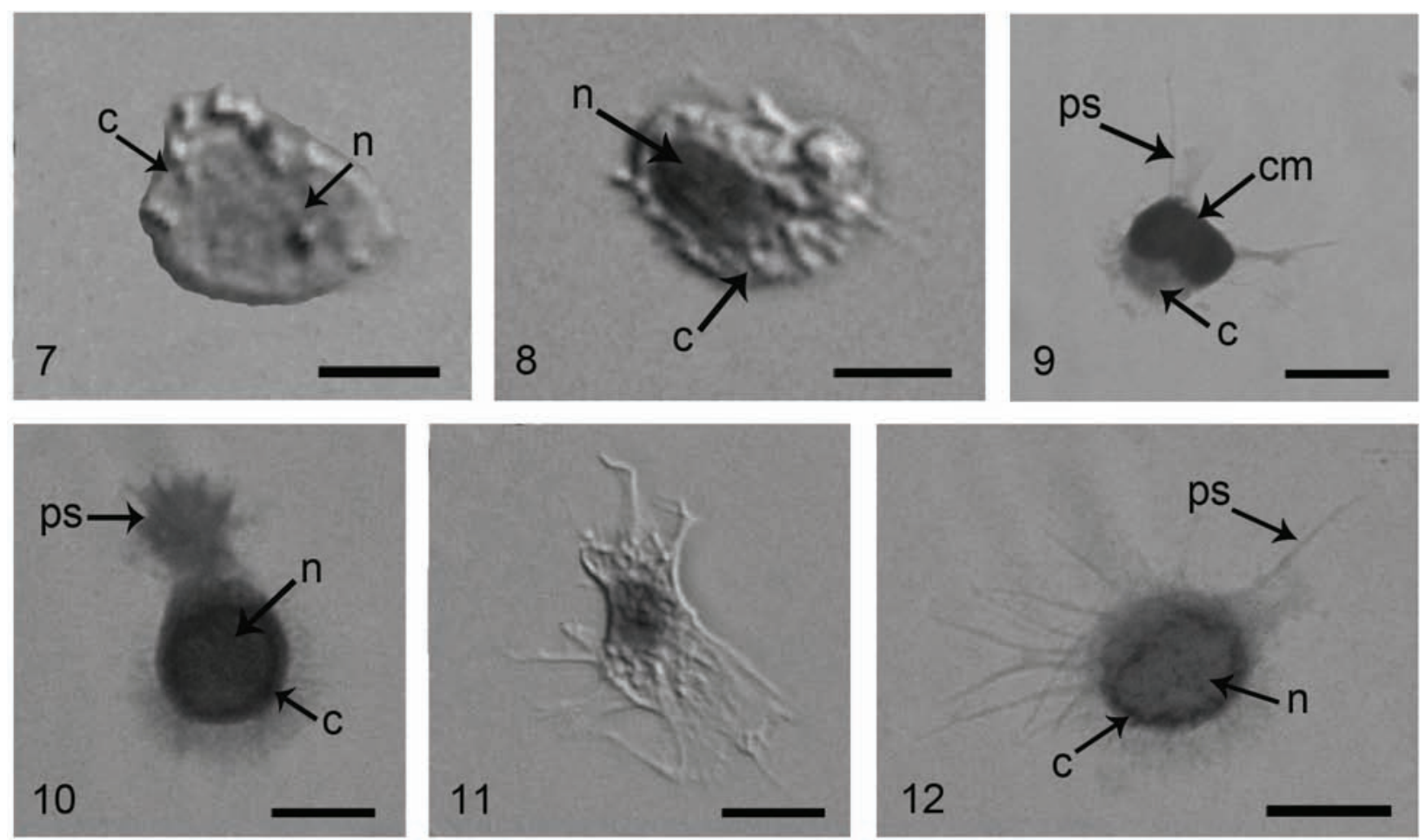

Figs 7-12. Tipos de hemócitos encontrados em indivíduos de Bradybaena similaris (Fèrussac, 1821): 7, célula redonda; 8, hialinócito; 9, hialinócito em divisão; 10-12, granulócitos (c, citoplasma; cm, célula em mitose; n, núcleo; ps, pseudópodes). Barra=25 $\mu$ m. 


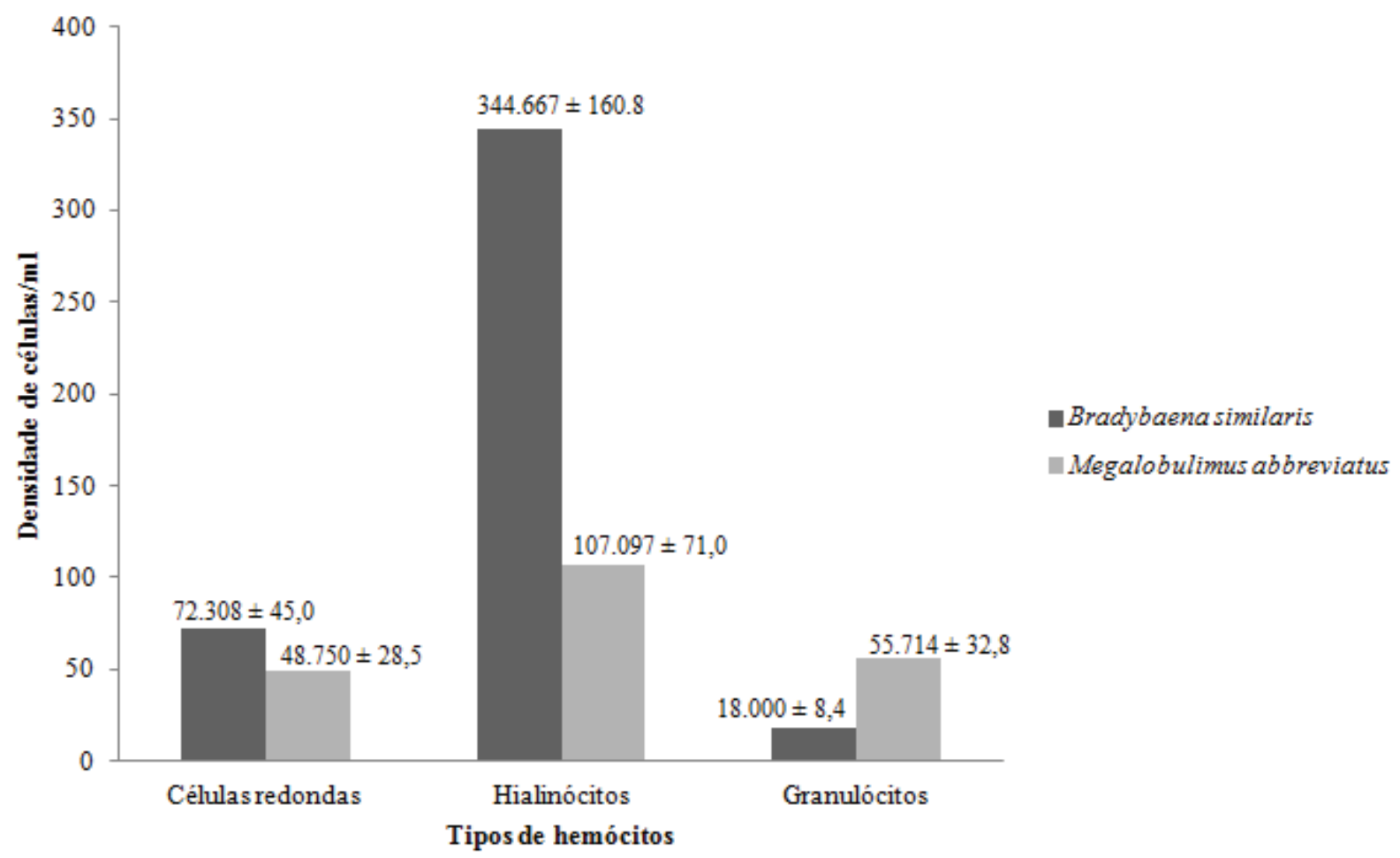

Fig. 13. Densidade média e desvio padrão das células/ml dos três tipos celulares encontrados na hemolinfa dos indivíduos das espécies Megalobulimus abbreviatus (Bequaert, 1948) e Bradybaena similaris (Fèrussac, 1821).

Tab. I. Tipos celulares, diâmetro médio, desvio padrão (DV), diâmetro total máximo e mínimo, diâmetro do núcleo e desvio padrão (DV), dos hemócitos encontrados na hemolinfa de Bradybaena similaris (Fèrussac, 1821) e Megalobulimus abbreviatus (Bequaert, 1948). Unidade de medida em $\mu \mathrm{m}$.

\begin{tabular}{lccc|ccc}
\hline & \multicolumn{3}{c|}{ Bradybaena similaris } & \multicolumn{3}{c}{ Megalobulimus abbreviatus } \\
Tipos celulares & Células Redondas & Hialinócitos & Granulócitos & Células Redondas & Hialinócitos & Granulócitos \\
\hline Número de hemócitos medidos & 52 & 149 & 69 & 50 & 124 & 186 \\
Diâmetro médio/DV & $10,7 \pm 3,87$ & $20,0 \pm 5,83$ & $25,4 \pm 9,8$ & $11,7 \pm 2,8$ & $21,5 \pm 6,1$ & $30,5 \pm 7,51$ \\
Diâmetro máximo total & 25 & 40 & 52,5 & 17,5 & 42,5 & 50 \\
Diâmetro mínimo total & 5,0 & 10 & 7,5 & 7,5 & 10 & 17,5 \\
Diâmetro médio do núcleo/DV & $6,6 \pm 3,44$ & $8,57 \pm 3,56$ & $9,89 \pm 3,74$ & $7,2 \pm 2,3$ & $10,1 \pm 3,3$ & $11,4 \pm 3,8$ \\
\hline
\end{tabular}

observaram-se células com mais de um núcleo em $B$. similaris, cerca de $6,5 \%$, sugerindo uma divisão atípica (Fig. 9). Os hialinócitos de ambas espécies tiveram o diâmetro médio semelhante entre as células, com variação igualmente equivalente (Tab. I). No entanto, verificamos diferença significatica $(p<0,0001)$ quanto ao diâmetro dos hialinócitos de M. abbreviatus e B. similaris. O diâmetro médio do núcleo dos hialinócitos de M. abbreviatus foi um pouco maior do que em $B$. similaris, sendo essa diferença significativa $(p<0,0007)$.

Os granulócitos (Figs 4-6; 10-12) são células polimórficas com perfil circular a fusiforme. Em ambas espécies, alguns granulócitos com formato fusiforme (Fig. 5) foram observados. A maioria dos granulócitos possui longas projeções citoplasmáticas e núcleo grande, geralmente excêntrico, e com variação no formato. Possuem grânulos basófilos no citoplasma, com número e distribuição variáveis, podendo se localizar na periferia ou no centro da célula. O diâmetro médio dos granulócitos foi semelhante entre as espécies estudadas, mas se mostrou um pouco maior para M. abbreviatus (Tab. I). Essa diferença entre o diâmetro dos granulócitos não foi significativa ( $p=0,77)$. O diâmetro do núcleo dos granulócitos apresentou-se semelhante para as duas espécies, não tendo sido detectadas diferenças significativas $(p=0,83)$.

Densidade e porcentagem dos hemócitos. O tipo celular com maior densidade na hemolinfa, em ambas as espécies, foram os hialinócitos (Fig. 10). A média da densidade total de hemócitos foi de 197.813 células/ml para M. abbreviatus e de 416.333 células/ml para B. similaris. Corroborando com a densidade, o tipo celular com maior porcentagem em $B$. similaris foi o hialinócito $(54,9 \%)$, seguido pelo granulócito $(25,4 \%)$ e pelas células redondas (19,1\%). O mesmo não ocorreu em M. abbreviatus, que teve maior porcentagem de granulócitos $(51,8 \%)$, hialinócitos $(34,5 \%)$ e as células redondas (13,9\%). 


\section{DISCUSSÃO}

Neste estudo foram observados, descritos e quantificados três tipos de hemócitos em Bradybaena similaris e Megalobulimus abbreviatus: as células redondas, os hialinócitos e os granulócitos. Quanto à morfologia dos hemócitos, os resultados deste estudo corroboram com o que já havia sido observado por GEORGE \& FERGUSON (1950) para Busycon carica Gmelin, 1791, OTTAVIANI (1992) para Planorbarius corneus (Linnaeus, 1758), CHENG \& Guida (1980) para Bulinus truncatus (Audouin, 1827) e para algumas espécies de Biomphalaria (HARRIS, 1975; LoVERDE et al., 1982; JoKy et al., 1983; NodA \& LoKer, 1989; BARRACO et al., 1993; CAVALCANTI et al., 2012). Estes autores descrevem os hemócitos como células morfologicamente distintas, com mais de um tipo presente na hemolinfa dos gastrópodes pulmonados. No entanto, Sminia (1972), SMinia \& BARENDSEn (1980), SMinia et al. (1981, 1983), Dіккевоом et al. (1984), AмеN et al. (1991), vAN DER KNAAP et al. (1993), SuREsh et al. (1994) e Russo \& LAGADIC (2004), que estudaram os hemócitos de espécies de Lymnaea, caracterizaram apenas um tipo celular com diferentes estágios de desenvolvimento.

Os hemócitos apresentaram poucas diferenças morfológicas entre as espécies neste estudo, especialmente relacionadas à ocorrência de pequenas projeções citoplasmáticas apenas em algumas células redondas de B. similaris, enquanto a presença de agrupamentos celulares de hialinócitos e granulócitos com formato fusiforme exclusivamente na hemolinfa de M. abbreviatus. Em relação à morfologia das células redondas, observamos semelhanças morfológicas entre as células redondas e as 'intermediárias' descritas por Diккевоом et al. (1984) em Lymnaea stagnalis (Linnaeus, 1758). Os hialinócitos e os granulócitos também se mostraram semelhantes morfologicamente com as células "espalhadas" descritas por Diккевоom et al. (1984).

As células redondas não variaram muito em relação ao seu tamanho, e os hialinócitos e os granulócitos foram as células que mais oscilaram em relação ao tamanho. Os hialinócitos apresentaram diferenças significativas entre as duas espécies estudadas. Embora tenham diâmetro semelhante com o encontrado para L. stagnalis por Dіккевоом et al. (1984), não podemos afirmar se essa semelhança é significativa ou não, devido às diferenças entre as metodologias utilizadas.

CAVAlCanti et al. (2012), ao estudarem a morfologia dos hemócitos de Biomphalaria glabrata (Say, 1818) e Biomphalaria straminea (Dunker, 1848), também observaram três tipos de hemócitos (sendo um tipo dividido em três morfotipos), e estes podem corresponder aos tipos de hemócitos descritos no presente estudo. $\mathrm{O}$ tamanho destas células foi diferente, um pouco menor do encontrado para as espécies aqui estudadas. Os tipos celulares mais observados por CAVALCANTI et al. (2012) também foram similares com os resultados obtidos para M. abbreviatus e B. similares, sendo o hialinócito tipo de hemócito mais encontrado. Mas esses resultados não podem ser comparados estatisticamente devido às diferenças no modo de amostragem e análise dos hemócitos.

As porcentagens dos tipos de hemócitos encontradas para ambas as espécies estudadas não foram semelhantes, com exceção das células redondas. As porcentagens de granulócitos na hemolinfa de M. abbreviatus foram maiores que as encontradas para B. similaris. Nesta, se encontrou maior porcentagem de hialinócitos, o que pode estar relacionado com seu estado físico, embora ambas espécies estudadas estarem saudáveis (livres de infecções). Esperava-se maior número de hialinócitos do que de granulócitos, pois estes últimos são responsáveis pela fagocitose de material estranho ao corpo dos gastrópodes. $\mathrm{O}$ que pode ter ocorrido para a maior porcentagem de granulócitos em $M$. abbreviatus é que os indivíduos podem ter sofrido algum tipo de estresse ambiental, o que pode acarretar no aumento dos granulócitos. Segundo Galloway \& Depledge (2001), a densidade e as funções dos hemócitos, como a fagocitose, por exemplo, poderiam ser afetadas por mudanças nas condições do ambiente. Os padrões de resposta dos hemócitos podem depender do tipo de estressor, e poderiam, portanto, ser utilizados como biomarcadores para discriminar alterações biológicas e químicas do ambiente.

Em outros estudos, como JEONG \& Heyneman (1976) e Abdul-Salam \& Michelson (1980) com B. glabrata e OtTAViani (1992) com $P$. corneus, os autores realizaram uma contagem do número total de hemócitos na hemolinfa. Os valores obtidos foram menores se comparados aos resultados obtidos para as espécies do presente estudo. Cheng \& Guida (1980), ao estudarem o gastrópode Bulinus truncatus rohlfsi (Clessin, 1886), obtiveram resultado similar com a densidade total de hemócitos obtido para M. abbreviatus.

Através das técnicas utilizadas neste estudo, foi possível diferenciar morfologicamente três tipos de hemócitos em B. similares e M. abbreviatus. No entanto, para o entendimento funcional e estrutural destas células, serão necessários mais estudos como da ultraestrutura e citoquímica dos hemócitos. Foi demonstrado que os hemócitos de $M$. abbreviatus e $B$. similaris possuem densidade diferente da maioria das espécies já estudadas, sendo os hialinócitos os mais frequentes. Este resultado pode estar relacionado a algum estresse que o animal tenha sofrido, o que pode provocar alterações na quantidade e no tipo de hemócito mais frequente na hemolinfa. No caso do parasitismo, seria interessante desenvolver um estudo comparativo com gastrópodes das mesmas espécies parasitados e não parasitados, para observar se realmente há diferenças entre a densidade e os tipos de hemócitos na hemolinfa durante uma infecção parasitária.

Agradecimentos. À CAPES pela bolsa de mestrado concedida à primeira autora. À pesquisadora Ingrid Heydrich (MCN, FZB-RS), pela concessão dos espécimes de $M$. abbreviatus. Ao Dr. José Felipe Amato e à técnica Juliana Troleis, pelo auxílio nas fotomicrografias. Aos Drs. Jorge Ernesto de Araújo Mariath e Rinaldo Pires dos Santos 
(Laboratório de Anatomia Vegetal, UFRGS), pela permissão de uso do microscópio para execução das fotomicrografias. A Dra. Samantha Seixas, pela revisão do texto.

\section{REFERÊNCIAS BIBLIOGRÁFICAS}

Abdul-Salam, J. M. \& Michelson, E. H. 1980. Biomphalaria glabrata amoebocytes: Assay of factors influencing in vitro phagocytosis. Journal of Invertebrate Pathology 36:52-59.

Amen, R. I.; Baggen, J. M. C.; Meuleman, E. A.; Wijsman-Grootendorst, A.; Boon, M. E.; Bezember, P. D. \& SMinia, T. 1991. Trichobilharzia ocellata: quantificatios of effects on haemocytes of the pond snail Lymnaea stagnalis by morphometric means. Tissue and Cell 23(5):665-676.

Ayres, M.; Ayres Jr., M.; Ayres, D. L. \& Santos, A. S. 2005. BioEstat 4.0. Aplicações Estatíticas nas Áreas de Ciências Biológicas e Médicas. Belém, Sociedade Civil de Mamirauá, MCT, Imprensa Oficial do Estado do Pará. 324p.

Bachère, E.; Gueguen, Y.; Gonzalez, M.; De Lorgeril, J.; Garnier, J. \& Romestand, B. 2004. Insights into the anti-microbial defense of marine invertebrates: the penaeid shrimps and the oyster Crassostrea gigas. Immunological Reviews 198(1):149-168.

Barbosa, L.; Silva, L. M.; Coelho, P. M. Z.; Santos, S. R. \& Fortes-Dias, C. L. 2006. Primary culture of the region of the amebocyte-producing organ of the snail Biomphalaria glabrata, the intermediate host of Schistosoma mansoni. Memórias do Instituto Oswaldo Cruz 101(6):639-643.

Barraco, M. A.; Steil, A. A. \& Gargioni, R. 1993. Morphological characterization of the hemocytes of the pulmonate snail Biomphalaria tenagophila. Memórias do Instituto Oswaldo Cruz 88(1):73-83.

Bayne, C. J. 1983. Molluscan Immunobiology. In: SAleuddin, A. S. M. \& Wilbur, K. M. orgs. The Mollusca. New York, Academic Press, Vol. 5, Physiology, Part 2. 407p.

Bezerra, F. S. M.; Nogueira-Machado, J. A.; Chaves, M. M.; Martins, R. L. \& Coelho, P. M. Z. 1997. Quantification of the number and phagocytary activity of hemocytes of resistant and susceptible strains of Biomphalaria glabrata and Biomphalaria tenagophila infected with Schistosoma mansoni. Revista do Instituto de Medicina Tropical 39(4):197-201.

Bezerra, F. S. M.; Nogueira-Machado, J. A.; Martins-Souza, R. L.; Chaves, M. M.; Correa, R. F. \& Coelho, P. M. Z. 2003. Effect of gamma radiation on the activity of hemocytes and on the course of Schistosoma mansoni infection in resistant Biomphalaria tenagophila snails. Memórias do Instituto Oswaldo Cruz 98(1):73-75.

Boulanger, N.; Bulet, P. \& Lowenberger, C. 2006. Antimicrobial peptides in the interactions between insects and flagellate parasites. Trends in Parasitology 22(6):262-268.

CARneiro, M. E. \& DAEMON, E. 1997. Caracterização dos tipos celulares presentes na hemolinfa de adultos de Rhipicephalus sanguineus (Latreille, 1806) (Ixodoidea: Ixodidae) em diferentes estados nutricionais. Revista Brasileira de Parasitologia 6(1):1-9.

. 2002. Estudo comparativo do aspecto da hemolinfa de algumas espécies de carrapatos (Acari, Ixodidae): descrição da variação hemocitária de adultos de Amblyomma cajennense (Fabricius) Koch. Revista Brasileira de Zoologia 19(Supl. 1):171-175.

Cavalcanti, M. G. S.; Filho, F. C.; Mendonça, A. M. B.; Duarte, G. R.; Barbosa, C. C. G. S.; Castro, C. M. M. B. de; Alves, L. C. \& BRAYNER, F. A. 2012. Morphological characterization of hemocytes from Biomphalaria glabrata and Biomphalaria straminea. Micron 43:285-291.

Cheng, T. C. \& Guida, V. G. 1980. Hemocytes of Bulinus truncatus rohlfsi (Mollusca: Gastropoda). Journal of Invertebrates Pathology 35(2):158-167.

DikKeboom, R.; Van der KnaAp, W. P. W.; Meuleman, E. A. \& Sminia, T. 1984. Differences between blood cells of juvenile and adult specimes of the pond snail Lymnaea stagnalis. Cell and Tissue Research 238:43-47.

Ford, S. E.; Kanaley, S. A. \& Littlewood, D. T. J. 1993. Cellular responses of oysters infected with Haplosporidium nelson: changes in circulating and tissue infiltrating hemocytes. Journal of Invertebrates Pathology 61(1):49-57.
Galloway, T. S. \& Depledge, M. H. 2001. Immunotoxicity in Invertebrates: Measurement and Ecotoxicological Relevance. Ecotoxicology 10:523.

George, W. C. \& Ferguson, J. H. 1950. The blood of gastropod mollusks. Journal of Morphology 86:315-324.

HARRIS, K. R. 1975. The fine structure of encapsulation in Biomphalaria glabrata. Annals of the New York Academy of Sciences 266:446464.

Humason, G. L. 1972. Animal Tissue Techniques. 3ed. W. H. San Francisco, Freeman and Company. 641p.

Jeong, K. H. \& Heyneman, D. 1976. Leukocytes of Biomphalaria glabrata - Morphology and behavior of granulocytic cells in vitro. Journal of Invertebrate Pathology 28:357-362.

Jeong, K. H.; Lie, K. J. \& Heyneman, D. 1983. The ultrastructure of the amebocyte producing organ in Biomphalaria glabrata. Developmental \& Comparative Immunology 7(2):217-228.

Joky, A.; Matricon-Gondran, M. \& Benex, J. 1983. Fine structural differences in the amoebocytes of Biomphalaria glabrata. Developmental \& Comparative Immunology 7(4):669-672.

KLEIN, J. 1989. Are invertebrates capable of anticipatory immune responses? Scandinavian Journal of Immunology 29(5):499-505.

LiE, K. J.; Heyneman, D. \& YaU, D. 1975. The origin of amebocytes in Biomphalaria glabrata. Journal of Parasitology 61(3):574-576.

LoVerde, P. T.; Gherson, J. \& Richards, C. S. 1982. Amebocytic accumulations in Biomphalaria glabrata: Fine Structure. Developmental \& Comparative Immunology 6(3):441-449.

Matricon-Gondran, M. \& Letocart, M. 1999. Internal defenses of the snail Biomphalaria glabrata. I. Characterization of hemocytes and fixed phagocytes. Journal of Invertebrates Pathology 74(3):224234.

MüLLER, G. 1956. Morphologie, Lebensablauf, und Bildungsort der Blutzellen von Lymnaea stagnalis. Zeitschrift fur Zellfordchung 44:519-556.

NodA, S. \& LoKer, E. S. 1989. Effects of infection with Echinostoma paraensei on the circulating hemocytes population of the snail Biomphalaria glabrata. Parasitology 98:35-41.

OTTAVIANI, E. 1992. Immunorecognition in the gastropod molluscs with particular reference to the freshwater snail Planorbius corneus (L.) (Gastropoda, Pulmonata). Italian Journal of Zoology 59(2):129-139.

Russo, J. \& LAGADIC, L. 2004. Effects of environmental concentrations of antrazine on hemocyte density and phagocytic activity in pond snail Lymnaea stagnalis (Gastropoda, Pulmonata). Environmental Pollution 127:303-311.

Santos, M. A. V. \& Diniz, J. A. P. 2009. Aspectos ultraestruturais de hemócitos de Biomphalaria glabrata Say (1818) (Gastropoda: Planorbidae) analisados sob microscopia eletrônica de transmissão. Acta Amazonica 39(3):707-712.

Santos, D. V. V.; Santos, M. A. V. \& Rodrigues, I. R. DE C. 2011. Hemocyte production in Biomphalaria glabrata snails after exposure to different Schistosoma mansoni infection protocols. Revista PanAmazônica de Saúde 2(2):33-38.

SminiA, T. 1972. Structure and function of blood and connective tissue cells of the freshwater pulmonate Lymnaea stagnalis studied by electron microscopy and enzyme histochemistry. Zeitschrift für Zellforschung 130:497-526.

Sminia, T. \& BARENDSEn, L. 1980. A comparative morphological and enzyme histochemical study on blood cells of the freshwater snails Lymnaea stagnalis, Biomphalaria glabrata, and Bulinus truncates. Journal of Morphology 165(1):31-39.

Sminia, T.; Van Der KnaAp, W. P. W. \& Vanasselt, L. A. 1983. Blood cell types and blood cell formation in gastropod molluscs. Developmental \& Comparative Immunology 7(4):665-668.

Sminia, T.; Winsemius, A. A. \& VAN DER KNAAP, W. P. W. 1981. Recognition of foreignness by blood cells of the freshwater snail Lymnaea stagnalis, with special reference to the role and structure of the cell coat. Journal of Invertebrate Pathology 38:175-183.

Suresh, P. G.; Reju, M. K. \& Mohandas, A. 1994. Factors influencing total haemocytes counts in freshwater gastropods. Comparative Haematology International 4:17-24.

VAN DER KNAAP, W. P. W. \& LoKer, E. S. 1990. Immune Mechanisms in Trematode-Snail Interactions. Parasitology Today 6(6):175-182. 
VAN DER KnAap, W. P. W.; Adema, C. M. \& SMinia, T. 1993. Invertebrate blood cells: Morphological and functional aspects of the haemocytes in the pond snail Lymnaea stagnalis. Comparative Haematology International 3:20-26.

Yoshino, T. P. 1976. The ultrastructure of circulating hemolymph cells of the marine snail Cerithidea californica (Gastropoda: Prosobranchiata). Journal of Morphology 150:485-494.
Zelck, U. E.; BeCKer, W. \& BAYNe, C. J. 1995. The plasma proteins of Biomphalaria glabrata in the presence and absence of Schistosoma mansoni. Developmental and Comparative Immunology 19(3):181194.

Recebido em 7 de março de 2014. Aceito em 25 de junho de 2014. ISSN 0073-4721

Artigo disponível em: www.scielo.br/isz 